\title{
BER Performance Comparison of Variable On-Off Keying and Variable Pulse Position Modulation Techniques
}

\author{
Mehmet Sönmez \\ Osmaniye Korkut Ata University, Department of Electrical Electronic Engineering, Osmaniye, Turkey \\ mehmetsonmez@osmaniye.edu.triD, \\ Received date: 19.03.2020, Accepted date: 30.06 .2020
}

\begin{abstract}
In wireless optical systems, Visible Light Communication (VLC) is one of the most popular communication systems. In this study, a Bit Error Rate (BER) performance comparison is given for Variable On-Off Keying (VOOK) and Variable Pulse Position Modulation (VPPM) which are extensively used in VLC systems. According to simulation and theoretical results, it is shown that the BER performances of systems are similar. In this paper, an ambient light noise is added to Additive White Gaussian Noise to extend the BER performance analysis. From simulation results, it is obtained that the impact of ambient light noise is very high for VOOK while it is quite poor for VPPM. Hence, the BER performance of VPPM has better than that of VOOK under ambient light noise.
\end{abstract}

Keywords: Dimming level, VLC, VOOK, VPPM

\section{Değiştirilebilir Aç-Kapa Anahtarlama ve Değiştirilebilir Darbe Konum Modülasyonu Tekniklerinin BHO Performans Karşılaştırılması}

\section{$\ddot{O} \mathbf{z}$}

Kablosuz optik haberleşme (KOH) sistemlerinde, Görünür Işık Haberleşme (GIH) en popüler haberleşme sistemlerinden birisidir. $\mathrm{Bu}$ çalışmada, görünür ışık haberleşme sistemlerinde yaygın olarak kullanılan değiştirilebilir darbe konum modülasyonu (VPPM) ve değiştirilebilir aç-kapa anahtarlama (VOOK) için bir Bit Hata Oranı (BER) performans karşılaştırılması verilmiştir. Benzetim ve teorik sonuçlara göre sistemlerin BER performanslarının benzer olduğu görülmüştür. Bu çalışmada, BER performans analizini genişletmek için, Eklenebilir Beyaz Gaussian Gürültüsüne bir ortam 1şı gürültüsü eklenmiştir. Benzetim sonuçlarından, VPPM'in ortam ışık gürültüsünden daha az etkileniyorken, VOOK oldukça yüksek etkilendiği görülmüştür. Bu nedenle, ortam sşı gürültüsü altında VPPM'in BER performans1, VOOK'ya göre daha iyidir.

Anahtar Kelimeler: Karartma seviyesi, GIH, VOOK, VPPM

\section{INTRODUCTION}

In recently, Wireless Optical Communication (WOC) are very popular systems due to its high bandwidth efficiency. Hence, the Visible Light Communication systems are an important candidate among the optical communication systems. In VLC systems, the optical signal is transmitted by a Light Emitted Diode (LED) while the signal is received by a photo detector. In many papers, the VLC can be employed for optical wireless communication (Huang et al.; 2019; Lin et al., 2020; Qin et al., 2020).

Many modulation techniques were proposed to transmit the data bits for VLC systems (Shiu et al., 1999; Meihong et al., 2009; Lee et al., 2011; Yang et al., 2012; Shalaby, 2013; Yoo et al., 2015). The On-
Off Keying (OOK), which uses high and low levels according to condition of data bit, is one of the simplest modulation techniques. Pulse Position Modulation (PPM), which is extensively preferred in VLC systems, is another modulation technique (Lee et al., 2011). In PPM method, the position of pulse is determined by using transmitted data bit. One of the PPM techniques is VPPM method which allows the adjustable dimming level for VLC systems (Yoo et al., 2015). Thanks to this technique, the dimming level of LED can be changed to provide power efficiency. Another PPM method is Overlapping PPM (OPPM) technique (Shalaby, 2013). This technique is proposed to increase the transmitted optical power. Therefore, the communication distance can be expanded for high optical power. In order to bandwidth and power efficiency, the 
Differential PPM (DPPM) technique is proposed for optical systems (Shiu et al., 1999). Although it provides lower bandwidth and power requirement, the slot length of DPPM can be changed according to data bits. The disadvantage causes frame synchronisation problems.

The Shortened PPM (SPPM) technique were investigated to provide data transfer for underwater optical communication systems (Meihong et al., 2009). The proposed technique reduces slot number of traditional PPM method. The variable dimming level method were employed for OPPM and OOK systems as traditional PPM (Yang et al., 2012). The adjusting of dimming level can be provided by Pulse Width Modulation (PWM). In order to increase the data rate of system, the low-density parity-check (LDPC) algorithm is integrated to the proposed OPPM-PWM method. A variable OPPM (V-OPPM) technique is improved to adjust lighting level of LED for VLC systems.

In recently, the dimming techniques have been also proposed for On-Off Keying systems (Lee et al., 2011). The VOOK is one of the dimming methods for OOK systems. The VOOK signal is obtained by changing duty cycle of high level signal. Additionally, the dimming level is adjusted by using PWM method. The normalized power consumption of VOOK is equal to VPPM. However, the PPM with higher order consumes lower power compared with VOOK. The spectral efficiency of VOOK is better than that of VPPM.

In literature, many modulation techniques is proposed for VLC systems. However, some comparisons must be given such as Bit Error Rate (BER) performance. The VPPM and VOOK modulation techniques are similar technique with respect to dimming levels. Hence, the paper gives a performance analysis for VPPM and VOOK. For BER performance, a channel must be integrated on the system (Bilim, 2019). The BER performance is obtained by changing the distance between transmitter and receiver. As simulation results, it is shown that BER performance of VOOK and VPPM can be changed dimming levels. For 50\% dimming level, the BER performance of VOOK and VPPM are equal to traditional 2-PPM and OOK techniques. Hence, BER performance of modulation techniques is same for theoretical analysis results. In simulation results, the BER performances of two systems are similar with respect to distance between receiver and transmitter for all dimming levels. The BER difference between VOOK and VPPM is appeared while the VOOK receiver system unknowns the threshold value. Although two systems have similar BER performance, the VOOK need threshold value to estimate data bit. Hence, the BER performance of VOOK is poor under ambient light compared with VPPM.

\section{MATERIAL AND METHODS \\ Led lighting}

In VLC, the LED is driven by current. By using the amplitude or duty cycle of current, the dimming level of LED can be changed to provide data transfer for modulation techniques. Many dimming technique was proposed for VLC systems such as analogue, digital and hybrid techniques. The transmitted optical power changes for different dimming level.

The transmitted optical power is one of the most significant parameters because it determines both communication distance and BER performance. The transmitted average optical power can be given by (Barry, 1994),

$$
P_{t}=\lim _{T \rightarrow \infty} \frac{1}{2 T} \int_{-T}^{T} x(t) d t
$$

where, $\mathrm{P}_{\mathrm{t}}$ and $\mathrm{x}(\mathrm{t})$ are represented transmitted power and amplitude, respectively. By changing the amplitude or duty cycle of signal, the dimming level can be adjusted. For example, the analogue dimming technique adjusts current amplitude of LED while digital dimming is obtained by duty cycle of signal. Although $\mathrm{P}_{\mathrm{t}}$ is transmitted power from LED, the received power $\left(\mathrm{P}_{\mathrm{r}}\right)$ is different from transmitted power due to attenuations and interferences. In particular, the attenuations are obtained due to distance between transmitter and receiver. Hence, the average received optical power is as follows:

$$
\mathrm{P}_{\mathrm{r}}=\mathrm{H}(0) \mathrm{P}_{\mathrm{t}}
$$

where, $\mathrm{H}(0)$ is denoted as channel DC gain. It depends on incidence angle $\psi$, irradiance angle $\phi$, Lambertian radiant intensity $\mathrm{R}(\phi)$, distance $\mathrm{d}$, the order of Lambertian emission $\mathrm{m}$, concentrator gain $\mathrm{g}(\psi)$, detector area A, optical filter gain $\mathrm{T}(\psi)$ and width of Field-of-View (FOV) of received system 


$$
\mathrm{H}(0)=\left\{\begin{array}{ll}
\frac{\mathrm{A}(\mathrm{m}+1)}{2 \pi \mathrm{d}^{2}} \cos ^{\mathrm{m}}(\phi) \mathrm{T}_{\mathrm{s}}(\psi) \mathrm{g}(\psi) \cos (\psi) & ; 0 \leq \psi \leq \Psi_{\mathrm{c}} \\
0 & ; \Psi_{\mathrm{c}}<\psi
\end{array}\right\}
$$

世c (Barry, 1994; Komine et al., 2004; Ghassemlooy et al., 2012). The channel DC gain can be expressed by (3). From Eq. (3), it is shown that the received optical power is affected by many parameters. The parameters can be simply adjusted for simulation environment however, the system parameters are unstable for practical environment. In particular, the line of sight must be provided to avoid high attenuation for LED and photodiode.

\section{VOOK technique}

VOOK technique was proposed to provide power efficiency for VLC systems. Compared with traditional OOK, VOOK reduces duty cycle of high level for lesser 50\% dimming while it increases duty cycle of low level for more $50 \%$ dimming level. Hence, the threshold level can be changed with respect to dimming level. In other way, the related slots for threshold can be changed according to dimming level. The dimming level affects the BER performance of OOK system.

In Table I, a codeword is given to observe the dimming level with respect to slot condition.
According to table, the ten slots is used to vary the dimming level from $0 \%$ to $100 \%$. However, the data cannot be transmitted at $0 \%$ and $100 \%$ dimming levels because all slots are filled as logical ' 0 ' or ' 1 '. Hence, the data bit cannot change the status of slot. The status of slot is exactly stable at these dimming levels. In another levels, the data bit changes the conditions of some slots according to data bits. In Table, $\delta_{\text {OOK }}$ is defined as dimming level of OOK method. The $\delta_{\mathrm{f}}, \mathrm{d}, \mathrm{F}$ and $\mathrm{N}_{\mathrm{s}}$ are presented as number of fixed slots, data bit, logical level of fixed slots and total slot number, respectively. The dimming level can be expressed by,

$\delta_{\mathrm{OOK}}=\frac{\mathrm{F} * \delta_{\mathrm{f}}+\left(\mathrm{N}_{\mathrm{S}}-\mathrm{F}\right) * 0.5}{\mathrm{~N}_{\mathrm{S}}}$

From (4), the dimming level of OOK technique can be obtained. From Equation and table, it is shown that traditional OOK system has 0.5 dimming level. It is expected that BER performance of traditional OOK has better than that of others because the percentage of data bit is higher than that of other dimming levels.

Table 1. VPPM and VOOK Codeword with respect to dimming level

\begin{tabular}{|c|c|c|c|}
\hline \multirow{2}{*}{$\delta$} & \multirow{2}{*}{$\begin{array}{c}\text { Codeword } \\
\text { (VOOK) }\end{array}$} & \multicolumn{2}{|c|}{ Codeword (VPPM) } \\
\hline & & Data Bit 0 & Data Bit 1 \\
\hline 0 & 0000000000 & 0000000000 & 0000000000 \\
\hline 0.1 & dd00000000 & 1000000000 & 0000000001 \\
\hline 0.2 & dddd000000 & 1100000000 & 0000000011 \\
\hline 0.3 & dddddd 0000 & 1110000000 & 0000000111 \\
\hline 0.4 & dddddddd 00 & 1111000000 & 0000001111 \\
\hline 0.5 & dddddddddd & 1111100000 & 0000011111 \\
\hline 0.6 & dddddddd 11 & 1111110000 & 0000111111 \\
\hline 0.7 & dddddd 1111 & 1111111000 & 0001111111 \\
\hline 0.8 & dddd111111 & 1111111100 & 0011111111 \\
\hline 0.9 & dd11111111 & 1111111110 & 0111111111 \\
\hline 1 & 1111111111 & 1111111111 & 1111111111 \\
\hline
\end{tabular}




\section{VPPM technique}

The dimming level of Pulse Position Modulation technique can be varied by PWM method like VOOK. By generating of dimming signal, the VPPM method is used bit condition compared with VOOK. The VPPM generates two signals for data bit ' 0 ' and ' 1 ' while the VOOK only changes the logical level of slot.

In Table I, VPPM dimming methods are given. As shown in the Table, there are two conditions compared with VOOK. VPPM directly changes duty cycle of slot for dimming level. The ten slots are given to observe dimming levels. The dimming level varies exactly $10 \%$ when the condition of one slot is changed.

\section{BER performance for vook and vppm techniques}

In this section, we give the mathematical foundations of VOOK and VPPM to compare the BER performances. The two modulation methods provide the variable dimming control for LED driver signal. The On-Off Keying technique is equal to $50 \%$ dimming level of VOOK. In the same way, 2 PPM technique can be obtained if the dimming level of VPPM can be adjusted 50\% dimming level. The traditional OOK has same BER performance as traditional 2-PPM (Ghassemlooy et al., 2012).

For 2-PPM, the $\mathrm{M}$ value is equal to 1 if $\mathrm{L}$ is equal to $2^{\mathrm{M}}$. The PPM technique can be applied as M-ary modulation techniques for visible light communication systems. The $\mathrm{M}$ value determines slot number in one period of modulation signal. Additionally, the location of filled slot can be determined by using of decimal value of data signal. The dimming level changes the result of integration of modulated signal hence, the BER performance is affected by dimming level of modulation signal. In meanwhile, the BER performance can be changed with respect to dimming level. For all dimming levels, the BER performances of VOOK and VPPM must be same due to weight of dimming levels with respect to data 0 and 1 conditions. For VOOK technique, the weight difference between data 0 and 1 can be written by,

$$
\begin{aligned}
& \mathrm{x}_{\mathrm{r}}=\sum_{0}^{2 * \delta * \mathrm{~N}} \mathrm{a} \text { if } \delta \leq 0.5 \\
& \mathrm{x}_{\mathrm{r}}=\sum_{0}^{2 *(1-\delta) * \mathrm{~N}} \mathrm{a} \text { elsewhere }
\end{aligned}
$$

where $\mathrm{N}$, a can be represented received sample number for one period and received signal value, respectively. In this expression, we assume that received signal is noiseless signal. The summing result is equal to zero if data bit=' 0 '. For data bit='1', $\mathrm{x}_{\mathrm{r}}$ can be expressed as,

$$
\begin{array}{ll}
\mathrm{x}_{\mathrm{r}}=2 * \delta * \mathrm{~N} * \mathrm{a} & \text { if } \delta \leq 0.5 \\
\mathrm{x}_{\mathrm{r}}=2 *(1-\delta) * \mathrm{~N} * \mathrm{a} & \text { elsewhere }
\end{array}
$$

From (8), the threshold value can be obtained by,

$$
\begin{array}{ll}
\mathrm{th}_{\mathrm{r}}=\delta * \mathrm{~N} * \mathrm{a} & \text { if } \delta \leq 0.5 \\
\mathrm{th}_{\mathrm{r}}=(1-\delta) * \mathrm{~N} * \mathrm{a} & \text { elsewhere }
\end{array}
$$

If data bit is equal to ' 0 ' for VPPM, the summing of received signal can be written by,

$\mathrm{x}_{\mathrm{r} 1}=0$

$\mathrm{x}_{\mathrm{r} 0}=\sum_{(1-\delta) * \mathrm{~N}}^{\mathrm{N}} \mathrm{a}=\delta * \mathrm{~N} * \mathrm{a}$

If data bit is equal to ' 1 ' for VPPM, the summing of received signal can be re-written by,

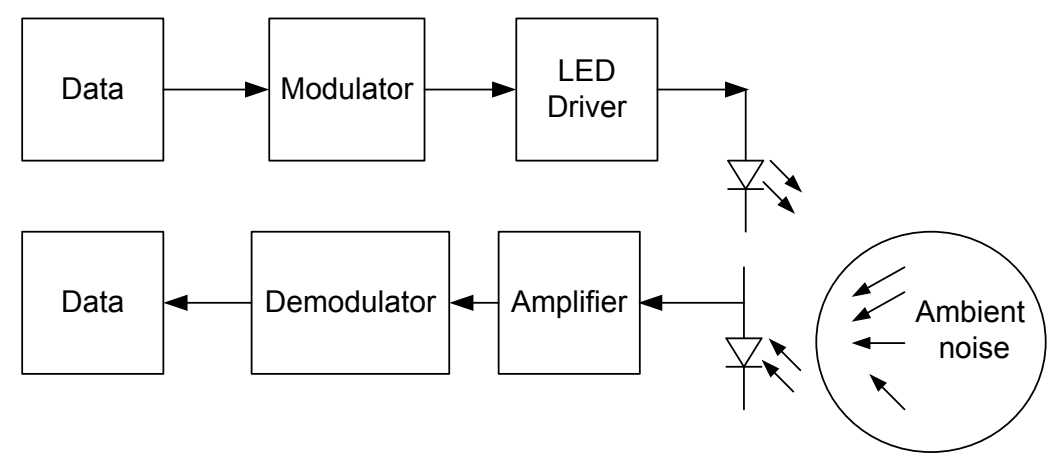

Figure 1. The system model 


$$
\begin{aligned}
& \mathrm{x}_{\mathrm{r} 1}=\sum_{0}^{\delta * \mathrm{~N}} \mathrm{a}=\delta * \mathrm{~N} * \mathrm{a} \\
& \mathrm{x}_{\mathrm{r} 0}=0
\end{aligned}
$$

From (7)-(9), it is shown that the distance between data bit ' 0 ' and ' 1 ' is equal to $\delta^{*} \mathrm{~N}^{*} \mathrm{a}$. Hence, the BER performances of VOOK and VPPM methods must be same. The distance can be varied for VOOK when an ambient light is added to modulated signal. The ambient light can be considered as DC-offset. The BER performance is decreasing since the level of ambient light cannot known by traditional VOOK system.

In Figure 1, the system model is given under ambient light noise. The modulator and demodulator can be adopted to VOOK or VPPM. The amplifier raises the current amplitude of photodiode.

\section{RESULTS AND DISCUSSION}

In this section, we give the simulation results of VOOK and VPPM modulated signals. The BER performance is measured by MATLAB simulation environment. The distance between receiver and transmitter is changed to obtain BER performance. The standard deviation of noise is selected as 0.63.
The BER value is changed both standard deviation of noise and distance between transmitter and receiver. In Figure 2.a, it is shown BER performances of VOOK and VPPM techniques. As shown in the figure, the simulation BER results are very similar. The condition is mentioned in Eq. (7)(9). From Equations, it is expected that the BER performance of VOOK and VPPM is similar. The simulation results are supported the Eq. (7)-(9).

We added a DC offset to obtain BER performance of VOOK and VPPM under ambient light effect. The DC offset is added to signals respect with the power ratio. The power ratio is presented as S/AN in the figures. In Figure 2.b, 2.c and 2.d, the S/AN is changed while the distance and standard deviation of noise is constant. As shown in the figures, the BER performance of VOOK reduces when the S/AN is increased. However, the BER performance of VPPM can not be affected from ambient noise because the ambient noise is added to both first slot and second slot of VPPM signal. Therefore, the difference between integration of first slot and second slot doesn't change according to Eq. (8) and (9).

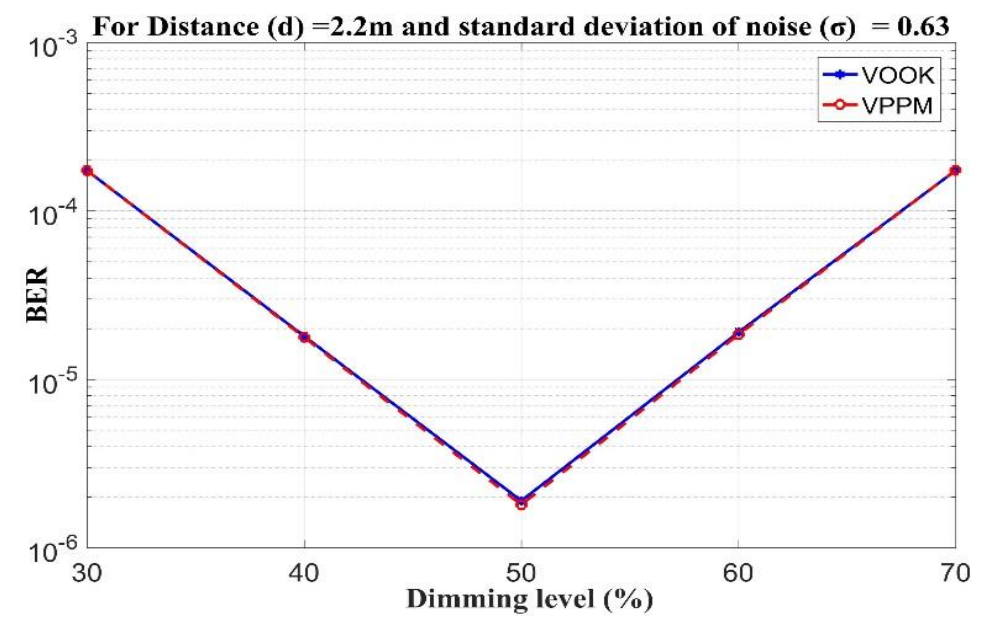

(a) 
DOI. 10.29132/1jpas. 705563

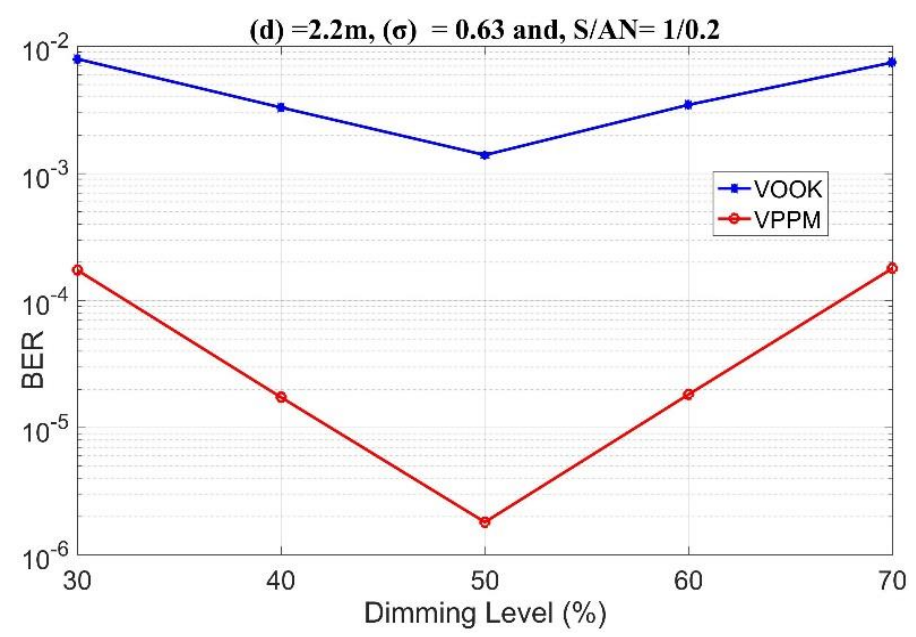

(b)

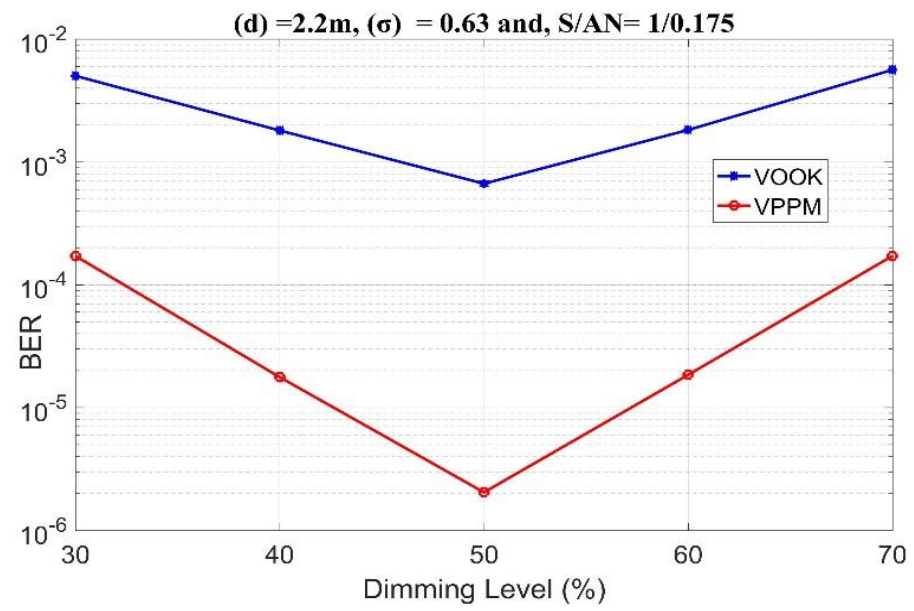

(c)

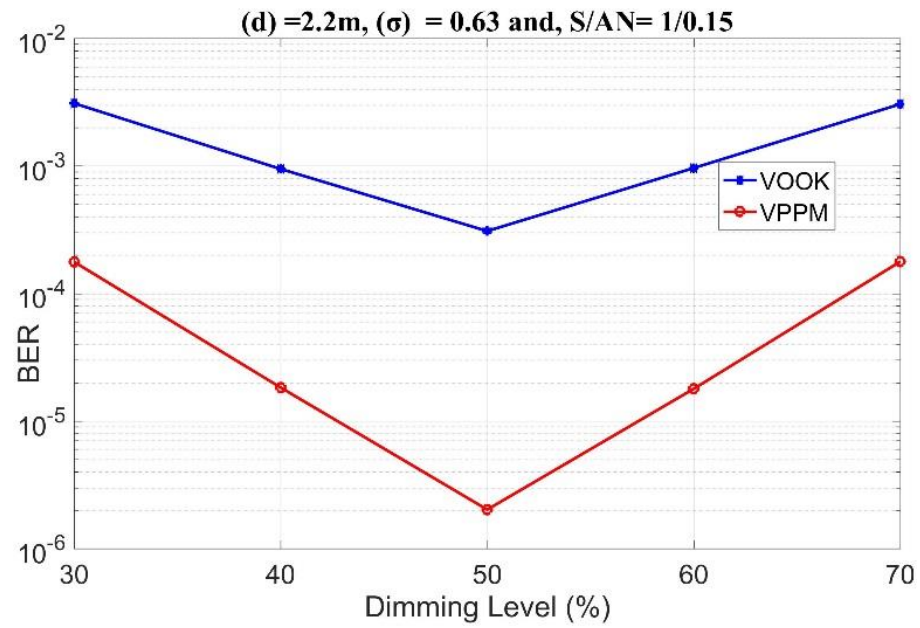

(d)

Figure 2. BER performance of VOOK and VPPM techniques. a) BER result for $d=2.2 \mathrm{~m}$ and $\sigma=0.63$ without ambient noise. b) BER result for $\mathrm{S} / \mathrm{AN}=1 / 0.2 \mathrm{c}$ ) BER result for $\mathrm{S} / \mathrm{AN}=1 / 0.175 \mathrm{~d}$ ) BER result for $\mathrm{S} / \mathrm{AN}=1 / 0.15$ 
As shown in Figure 2, the BER performance of VPPM is about $10^{-5}$ while BER performance of VOOK is approximately $10^{-3}$. The BER performance of VPPM cannot affected by ambient light noise while the VOOK has BER performance between $10^{-3}$ and $10^{-4}$.

\section{CONCLUSION}

In this paper, we analyse the BER performances of VOOK and VPPM techniques. According to Eq (7)-(9), the BER performance of modulation techniques must be similar. The Figure 2.a is provided the equations. As shown in the figure, BER results are similar. Moreover, we observed the BER performance of techniques under ambient noise. The ambient noise is considered as a DC offset signal. The BER performance of VOOK is reducing while the ambient noise is increased. However, the BER performance of VPPM signal cannot be affected from this condition since the ambient light noise is added to both first slot and second for VPPM. The BER performance of VOOK can be improved by using filter that rejects ambient light noise. However, the ambient light noise is reduced the effect of direct received signal on photodiode for practical systems, hence it can be shown that effect of received signal is reduced. This case affects the BER performance of VPPM. In future, the adaptive threshold detection methods can be improved for VOOK method. Additionally, both theoretical and practical solutions can be given.

\section{REFERENCES}

Barry, J.R., 1994. Wireless infrared communications. Kluwer Academic Press, USA.

Bilim, M., 2019. A performance study on diversity receivers over $\kappa-\mu$ shadowed fading channels. International Journal of Electronics and Communications, 112:1-8.

Ghassemlooy, Z., Popoola, W., Rajbhandari, S., 2012. Optical wireless communications: system and channel modelling with MATLAB. CRC Press, USA.

Huang, T., Yang, W., Wu, J., Ma, J., Zhang, X., Zhang, D., 2019. A survey on green $6 \mathrm{~g}$ network: architecture and technologies. IEEE Access, 7:175758-175768.

Komine, T., Nakagawa, M., 2004. Fundamental analysis for visible-light communication system using LED lights. IEEE Transactions on Consumer Electronics, 50:100-107.
Lee, K., Park, H., 2011. Modulations for visible light communications with dimming control. IEEE Photonics Technology Letters, 23:1136-1139.

Lin, B., Tang, X., Ghassemlooy, Z., 2020. A power domain sparse code multiple access scheme for visible light communications. IEEE Wireless Communications Letters, 9:61-64.

Meihong, S., Xinsheng, Y., Zhangguo, Z., 2009. The Modified PPM Modulation for Underwater Wireless Optical Communication. International Conference on Communication Software and Networks, China, February 2009.

Qin, Y., Guo, D., Lin, X., Cheng, G., 2020. Design and optimization of VLC enabled data center network. Tsinghua Science and Technology, 25: 82-92.

Shalaby, H.M.H., 2013. Performance analysis of SACOCDMA systems adopting overlapping PPM schemes. Journal of Lightwave Technology. 31(12):1856-1866.

Shiu, D., Kahn, J.M., 1999. Differential pulse-position modulation for power-efficient optical communication. IEEE Transactions on Communications, 47:1201-1210.

Yang, A., Li, X., Jiang, T., 2012. Enhancement of LED indoor communications using OPPM-PWM modulation and grouped bit-flipping decoding. Optics Express, 20:10170-10179.

Yoo, J.H., Kim, B.W., Jung, S.Y., 2015. Modelling and analysis of M-ary variable pulse position modulation for visible light communications. IEET Optoelectron, 9:184-190. 